\title{
HOW TO DO THINGS WITH ACTIVO DESENCANTO: EL DISCURSO DEL DESENCANTO EN LOS DE ABAJO DE MARIANO AZUELA
}

\author{
POR \\ LAURA V. SÁNDEZ \\ Graduate Center-CUNY
}

Es indispensable que el pueblo conozca la conducta de todos, para que serena y desapasionadamente, con perfecto conocimiento de causa, pueda juzgar a unos y a otros. "Actos", La Prensa, 8 de febrero de 1915

Si bien la pérdida de una ilusión puede o no producir desencanto en el sujeto y seguramente debe de haberlo ocasionado en Mariano Azuela, podríamos decir que, constituyéndose como un lenguaje performativo dentro del cual opera una subjetividad, el desencanto excede la categoría de producto que expresa un estado. La "performance"1 del discurso del desencanto que hace Alberto Solís en la novela Los de abajo (1915) de Mariano Azuela marca la pertenencia de éste a la nación ${ }^{2}$ de hombres honrados y

1 Utilizo el término "performance", y no puesta en escena, actuación, etc., porque este concepto se refiere a una conducta cuyo carácter ilocutivo consiste en repetir un comportamiento sostenido por medios discursivos. Asimismo, dado que baso mi marco teórico en Judith Butler, mantengo la especificidad que la autora le da al término: "Performativity describes this relation of being implicated in that which one opposes, this turning of power against itself to produce alternative modalities of power, to establish a kind of political contestation that is not a "pure" opposition" (Bodies that Matter 241) [La performatividad describe esa relación de estar implicado en aquello a lo que uno, aparentemente, se opone, ese modo de volver el poder contra sí mismo para producir modalidades alternativas de poder que no son pura oposición] (Cuerpos 339). Este "tipo de contestación política que no es pura oposición" es lo que me lleva a incluir núcleos de desencanto provenientes de sujetos carrancistas o porfiristas para analizar el desencanto como aquella conducta dos veces actuada que no es pura oposición. Para la relación de "performance" con la promesa de subjetividad véase Unmarked: The Politics of Performance de Peggy Phelan (151). Para más información en cuanto al concepto "performance" puede verse "Hacia una definición de Performance" (2001) de Diana Taylor o el artículo de Catherine Larson (2011) en Latin American Theatre Review.

2 Max Weber señala en que aparte de los intereses materiales explícitos hay en determinados círculos privilegiados, ciertos intereses en parte indirectamente materiales y en parte ideológicos en los que "the naked prestige of 'power' is unavoidably transformed into other special forms of prestige and especially into the idea of the "nation." (Essays in Sociology, [Ed. 1946] 172) [el prestigio, sin más, del poder se 
conscientes de su situación histórica. Según el filósofo y sociólogo Carlos Thiebaut, "la primera consecuencia del desencanto, [en el sentido que le da Max Weber], es que entiende que las incertidumbres son motivo de una reacción que contiene una moral y que la conforma. Es una interpelación, no sólo teórica sino práctica" (25). Siguiendo esta perspectiva, abordaremos el desencanto como figura de una identidad imaginaria de una agencia ética y para eso nos centraremos en la reinterpretación del concepto de interpelación de Althusser que desarrolla Judith Butler. Dado que de acuerdo a Butler la creencia en la ley que hace posible la subjetivación del individuo se halla ligada a una vinculación apasionada a la ley, la vinculación desapasionada que manifiesta Alberto Solís resulta significativa para una crítica literaria de análisis afectivo. (24) Como veremos más adelante la atribución de diferentes naturalezas a la vinculación del sujeto con la ley fue motivo de pugnas entre diversas formas de regulación social. Se limita este análisis al discurso del desencanto para presentar una problemática de análisis que incluya no sólo los cuerpos ausentes o presentes en el texto de la Revolución Mexicana, sino también los sentimientos.

Los de abajo es considerada una novela de la Revolución que se caracteriza por una devaluación -o problematización- de los ideales épicos de la Revolución Mexicana y por la inclusión, hasta ese momento poco explorada, de una polifonía de voces discursivas en la que se ven reflejados los prejuicios de la época hacia "los que pensaron" y "los que actuaron", hacia la justicia y la fuerza, hacia la ley y el sistema de caudillaje. La novela se publicó primeramente en un periódico de El Paso, Texas -que no se distribuía en México (García 13) - ajustándose así al formato periodístico por entregas. Fue publicada fuera del país porque Azuela, que militaba como médico en las fuerzas villistas de Julián Medina desde octubre de 1914, tuvo que refugiarse luego de la derrota de Celaya (abril 1915). En 1916 salió en forma de libro pero ni siquiera el propio Azuela supo qué pasó con esta edición. En 1925, es publicada en un medio de difusión masiva y ahí se integra al cuerpo de la literatura mexicana. Un debate en torno a la existencia de una literatura viril iniciado en 1924 entre Francisco Monterde y Jiménez Rueda -al cual se sumó Victoriano Salado Álvarez y muchos otros en $E l$ Universal Ilustrado y El Excelsior - generó las condiciones para que saliera publicado al año siguiente en el Universal Ilustrado entre el 29 de enero y el 24 de febrero de 1925. El marco temporal de Los de abajo transcurre a lo largo de casi dos años. La primera parte abarca de mediados de 1913 hasta la toma de Zacatecas (23 de junio de 1914), la segunda transcurre entre junio de 1914 y la convención de Aguascalientes (octubre de 1914) y la tercera comienza con una carta fechada el 5 de mayo de 1915 y dura unos días.

transforma, inevitablemente, en otras formas especiales de prestigio, en especial la idea de "nación"] (traducción mía).

Revista Iberoamericana, Vol. LXXXI, Núm. 250, Enero-Marzo 2015, $125-139$ ISSN 0034-9631 (Impreso)

ISSN 2154-4794 (Electrónico) 
“LA RAZÓN ESTÁ EN VER LA FALSEDAD Y GROSERÍA, ROMPER LA ILUSIÓN”

En Los de abajo, unos personajes son sinceros y otros son conscientes, pero solamente Alberto Solís es las dos cosas. Parecería que Solís es un personaje mediador entre la falta de sentimientos de Cervantes y la falta de conciencia crítica de Demetrio Macías. Mientras que los de abajo, los hombres inmersos en la acción, poseen la facultad de ignorar la falta de verdad -en el sentido nietzscheano- ${ }^{3}$ Cervantes elige olvidar los valores a pesar de ser consciente de su historia en la revolución. Cervantes compagina su falta de escrúpulos con su falta de sentimientos y los de abajo articulan un sin fin de sentimientos con una falta de conciencia crítica. El autor da indicio de esta falta de conciencia crítica por medio de anécdotas como ésta: "Mire a mí no me haga preguntas que no soy escuelante... La aguilita que traigo en el sombrero usté me la dio... Bueno, pos ya sabe que nomás me dice: "Demetrio, haces esto y esto... ¡Y se acabó el cuento!" (122). Solís, por el contrario, no basa su obediencia en torno a una persona sino a un ideal. ${ }^{4}$ Hay un hábito sentimental específico que parece suministrar un saber, una convicción. La edición original de 1915 hace esto más explícito: "Me preguntará -agregó [Solís]- que por qué sigo a pesar de eso en la Revolución [...] porque un atavismo implacable y mi organización mental de idealista a outrance, de sentimentalista sin remedio, me han hecho creer, con toda la fuerza de una convicción, que todo mexicano que incline su cuello ante el gobierno del asesino Huerta, es un miserable y un indigno! ... ¡Contradicciones! ... ¡Tonterías! ¿Qué quiere usted?” (Folletín núm. 10; parte primera, capítulo XV) (172). Estas contradicciones y estas tonterías se hallan enmarcadas por el desencanto. No es lo que dice Solís sino la emoción que se le imprime a lo dicho lo que permite evaluar su carácter de metadiscurso de verdad. Ejemplo de esto es que la frase "iQué hermosa es la Revolución, aún en su misma barbarie!” (71) era atribuida a Cervantes hasta la edición de 1920, es decir, ha existido en dos lógicas valorativas distintas. La crítica ha tendido a interpretarla como una expresión de amor por la justicia, lo histórico, el reconocimiento. El desencanto que informa lo dicho por Solís deviene de su postura crítica ante la historia, dado que se encuentra entre la necesidad de olvidar la falta de verdad en la lucha para actuar y la necesidad de afirmarse como sujeto por medio del recuerdo de la falta de verdad.

3 Para Nietzsche el hombre debe alcanzar un equilibrio acorde a sus capacidades entre lo histórico y lo ahistórico. El hombre necesita de la historia, de la incapacidad de olvidar, para llegar a ser hombre pero necesita estar en contacto con la vida, lo ahistórico para actuar. "El hombre que actúa ama la acción infinitamente más de lo que en realidad merece ser amada" (47). "Poder sentir de manera no histórica conlleva a desarrollar una vida abstrayéndose de toda duración" (42).

4 Esto resulta significativo en términos de los estadios en el reconocimiento hegeliano. Los de abajo depositan su subjetividad en la subjetividad del líder carismático, no existe un mutuo reconocimiento, y Cervantes anula la subjetividad del otro y por lo tanto no alcanza la subjetivación del reconocimiento.

Revista Iberoamericana, Vol. LXXXI, Núm. 250, Enero-Marzo 2015, 125-139 ISSN 0034-9631 (Impreso)

ISSN 2154-4794 (Electrónico) 
El tema de la revolución frustrada que tuvo excepcional repercusión en la literatura de México, se inicia con Los de abajo (Fornet 4). Este desencanto "no está relacionado tanto con un estado de ánimo como con un cambio de perspectiva al historiar el proceso de la Revolución" (11). Se establecen dos tensiones paralelas que tienen que ver con la oposición entre la espontaneidad de ciertos personajes y la sofisticación de otros y, entre la honestidad del desencanto y el idealismo retórico. Azuela manifiesta su postura en cuanto a este idealismo retórico ejemplificado por Cervantes en una carta a Ernest Moore: "me ha sorprendido la similitud que se ha encontrado entre el tipo de Luis Cervantes y yo mismo ... En el [tipo] de Cervantes [he pretendido presentar] a uno de los especímenes más repugnantes de la fauna revolucionaria: el logrero de la revolución que sólo busca su medro personal y está listo a abandonar cualquier causa en cuanto la ve perdida" (Robe 216). La psicología del desencanto ve el discurso real como una ficción y a su vez, esta ficción tiene consecuencias reales que exceden lo racional.

El desencanto marca una relación no anulada, no resuelta con una pérdida de la ilusión, basada en una necesidad vital de reconocimiento. Según G. W. F. Hegel, el reconocimiento progresivo es una forma de alcanzar una vida moral que posibilite tanto la autonomía de la comunidad como la de los instrumentos de regulación social. El más alto reconocimiento funciona en Hegel como una mutua relación entre auto-conciencias en donde no hay una relación de poder unilateral.

\section{VINCULACIÓN DESAPASIONADA}

Considerar el desencanto como mera reacción al fracaso de la revolución cae en un error similar al que Judith Butler atribuye al concepto de interpelación de Althusser. Este es, considerar que uno (sujeto/desencanto) es producido por el otro (interpelación/ fracaso de la revolución). Consecuentemente, analizaré el sentimiento del desencanto, no como una reacción natural, sino como una respuesta subjetiva, buscando, no lo que significa, sino a qué tensiones da presencia. Aprovecho la idea de reconocimiento y legitimidad en la vinculación con la ley para introducir un análisis del desencanto que cree un espacio para evaluar un discurso de emoción fuera de su carácter expresivo a fin de considerar su carácter operativo, y por lo tanto su posibilidad de agencia. En lugar de observar la relación entre el sujeto y las ilusiones perdidas (marco privilegiado por el desencanto como producto) elijo observar la relación entre el sujeto y el desencanto a la luz de su vinculación con la ley. En lugar de observar qué se imaginó y no funcionó o se imaginó pero nunca existió, observo qué tipo de relación entre la legitimidad y el sujeto permitía el desencanto en relación a la vinculación con la ley.

En "La conciencia nos hace a todos sujetos", Judith Butler se basa en La fenomenología del espíritu de Hegel para introducir en el discurso de la interpelación el concepto de materia prima no discursiva. Este uso que hace Butler de Hegel me resulta oportuno

Revista Iberoamericana, Vol. LXXXI, Núm. 250, Enero-Marzo 2015, $125-139$ ISSN 0034-9631 (Impreso)

ISSN 2154-4794 (Electrónico) 
para un análisis en torno al desencanto con la Revolución Mexicana porque permite establecer el desencanto más allá de como "la razón en ver la ilusión" para ver qué tipo de agencia busca un autor al supeditar la posibilidad de reconocimiento a una materia no discursiva. Edward Casey afirma que la discusión del deseo en La fenomenología busca enfatizar cómo el deseo humano trasciende la necesidad biológica o los impulsos orgánicos (229). Casey señala que tanto en Lacan como en Hegel el sujeto se hace consciente de sí mismo al experimentar deseo y al reconocer que la imagen de sí mismo no refleja esta necesidad del deseo del otro (225). Mi punto es que el desencanto, como el deseo, marca un límite de irreductibilidad a la imagen y una necesidad de duración, pasaje y reconocimiento. El desencanto no excluye a otras auto-conciencias pero se constituye como una negación de la necesidad del deseo de "ciertos" otros. Por un lado, existe la irreductibilidad de la imagen de sí mismo al deseo de la otra modalidad de autoconsciencia autónoma. Y por el otro hay una necesidad del deseo de una modalidad de consciencia que no alcanza el deseo humano - que es esclava de sus apetitos-. Ambas conllevan a una indecibilidad del efecto instantáneo de la imagen de cosa sobre el sujeto. Hay un núcleo que excede la metáfora teológica.

Butler sugiere que Althusser olvida considerar la posibilidad de rehusar el llamado de la ley porque cae preso de la lógica de las metáforas teológicas (124). Pero mantiene la idea de que uno está "uno/a está ya, por así decir, en relación con la voz antes de responder a ella, está ya comprometido/a" (Mecanismos 125) para introducir la noción de "vinculación apasionada" y "espera apasionada" de la ley. A fin de relacionar el desencanto con una forma de vinculación a la ley que se presenta por medio de la teoría de Butler habría que probar que Azuela plantea el tema de la relación con la ley. Para eso incorporo fragmentos de otras de sus obras en un rango de 1909 a 1923, período que abarca desde un año antes de la Revolución a un año antes de su reconocimiento como escritor de la Revolución. La vinculación con la ley en Mala Yerba (1909) es diferente para los caciques que "no lo hurtan, lo heredan" (OC119-I), y para Marcela que obedeciendo a la interpelación de la ley del cacique desdice la ley del alcalde. (131) Su creencia en la ley obedece a un hábito, es una reacción: ante la mirada (llamada) de don Julián, Marcela -la querida de don Julián- niega el crimen de don Julián. Ni don Julián Andrade ni Marcela contemplan la obediencia hacia la ley, don Julián, porque los Andrade "con más ardides que el tinterillo, sabían salir libres de toda culpa” (125), y por lo tanto no se someten a la necesidad de probar inocencia, la fabrican; Marcela, porque "pesaba sobre ella el poder tremendo de la arrogante raza de violadores a quienes jamás ninguna de sus víctimas entregó a la justicia” (130). Butler afirma que la respuesta al llamado no se funda en una creencia que es una internalización de una ley externa sino que obedece a una necesidad de probar inocencia. La forma en que Butler mantiene una relación de complicidad con la ley presentando un espacio para la subjetividad es estableciendo una suerte de medio tiempo entre el llamado de la ley (el

Revista Iberoamericana, Vol. LXXXI, Núm. 250, Enero-Marzo 2015, $125-139$ ISSN 0034-9631 (Impreso)

ISSN 2154-4794 (Electrónico) 
policía en la analogía de Althusser) y la reacción del individuo que acude al llamado. Butler establece que primeramente existe un darse vuelta y luego un ir hacia la ley. De esta manera plantea el problema de la vinculación con la ley y la obediencia. El llamado de la ley no produce el acto de darse vuelta pero, no obstante, su promesa de identidad favorece esta respuesta.

El desencanto es un afecto a medio camino entre una promesa de identidad (ir hacia el reconocimiento) y la necesidad de probar inocencia hacia esa ley (el darse vuelta). En el desencanto el problema de la legitimidad de la obediencia que plantea la promesa de identidad no queda resuelto. El someterse a la necesidad de probar inocencia que Butler establece como sumisión primaria (16) nos habla de las categorías existentes en cuanto a la vinculación con la ley; es decir, aquello de lo cual se prueba inocencia nos habla de las posibles acusaciones dentro de un imaginario social.

Para hombres y mujeres, las formas de vinculación apasionada cubrían en 1915 diferentes ámbitos, pero coincidían en algunos de sus presupuestos. El periódico El pueblo del día 6 de octubre de 1914 publica en la misma página "Para ser amada. Renuncias provechosas" en la sección "Para las damas" y "La afectación" de tinte más político. En "Para ser amada" se aconseja: "renunciad a ser amadas, y, si continuáis amando, pensad que habéis escogido la mejor parte" (5); "con mucha frecuencia conseguimos esa simpatía tan deseada cuando ya no pensamos en ella...cuando tal vez no tengamos ningún interés en conseguirla" (énfasis mío). "La afectación” por el lado derecho de la página, aseveraba: "Los buenos, los sencillos, los espíritus nobles que sienten hondo, tienen el deber de pensar alto y de exteriorizar sus levantados sentimientos" (5). Algunas recomendaciones sentimentales aparecían a su vez en las secciones editoriales. La prensa del día 14 de octubre de 1915 condenaba "la neutralidad de los hombres conscientes" considerándola "a todas luces antipatriótica e incivil" ya que "la abstención política está reñida con la condición ciudadana del hombre, porque significa, marcada prueba de cobardía y falta absoluta de patriotismo" (De la Torre 3). Y más bien se demandaba una respuesta emocional en "El Sr. Carranza ante la Convención" cuando se afirmaba que: "La Nación y la historia esperan con ansia la respuesta de Francisco Villa para maldecir a quien no sepa ponerse al nivel de los dolores angustiosos de la Patria" (3). Podemos ver que el desencanto de Solís responde a las exigencias de la época: debía ser sentimental al mismo tiempo que parcial y activo, es decir, no podía caer en el nihilismo ya que esto estaba reñido con "la condición ciudadana".

El problema que se plantea en Los de abajo es que sólo los de abajo creen en la Revolución y esto se debe a una relación ingenua con la ley. Esta relación ingenua con la ley implica un tipo de obediencia que sacrifica el intelecto. En la prensa, la relación ingenua con las legalidades tiende a identificarse con "las masas de hombres incultos, pero movidos por un sentimiento de reivindicación" (Brioso y Candiani 3). La misma acusación de relación ingenua, pero no con la ley de la revolución sino con la de la nación,

Revista Iberoamericana, Vol. LXXXI, Núm. 250, Enero-Marzo 2015, $125-139$ ISSN 0034-9631 (Impreso)

ISSN 2154-4794 (Electrónico) 
se argumentaba un siglo antes. En 1820, el escritor mexicano José Luis Mora expresaba: "El pueblo ignorante, persuadido de su soberanía y careciendo de ideas precisas que determinen de un modo fijo y exacto el sentido de la palabra nación, ha creído que se debía reputar por tal toda reunión de individuos de la especie humana, sin otras calidades y circunstancias" (citado en Palti, La nación 135). En Los Caciques (1914) se articula un pensamiento semejante: “¡La ignorancia de las masas es la desgracia nacional! ¡Por la ignorancia de las masas llevamos cinco lustros de soportar la bota del dictador Porfirio Díaz!" (Azuela, Obras completas 806). Sin embargo, Solís, como individuo perteneciente a la clase culta, debe declararse inocente bajo argumentos diferentes: "Yo pensé una florida pradera el remate de un camino... Y me encontré un pantano. Amigo mío: hay hechos y hay hombres que no son sino pura hiel... Y esa hiel va cayendo gota a gota en el alma, y todo lo amarga, todo lo envenena. Entusiasmo, esperanzas, ideales, alegrías..., ¡Nada!” (61). El “ pecado” del que se presume inocente queda muy claro en las palabras de Rodríguez, el personaje honesto, comprometido y educado en Los Caciques, "la vergüenza más ignominiosa que la revolución de 1910 ha desnudado es una intelectualidad abyecta que arrastra su panza por el cieno" (Azuela, Obras completas 844). La metáfora bíblica se aplica a una lógica de emancipación: "Sabemos que hay dos clases de siervos en México, los proletarios y los intelectuales” (844).

Siguiendo el orden simbólico de Lacan, Butler afirma que el deseo es lo que le da continuidad a la interpelación, y que el hecho de que lo Imaginario no se corresponda con lo Real obedece a esta mediación del deseo: "Si la conciencia es una de las formas que adopta la vinculación apasionada a la existencia, entonces el fracaso de la interpelación se localiza precisamente en la misma vinculación apasionada que le permite funcionar" (Mecanismos 143). Butler remite a la estructura psíquica lo que Althusser atribuye a la estructura en términos marxistas. Una vez que uno entra en lenguaje, nuestro deseo esta mediado por el mismo. Nuestro deseo no llega nunca a ser "el nuestro" sino que es creado por fantasías que están atrapadas en ideologías culturales (Felluga n.a.). "Este amor no se encuentra más allá de la interpelación; por el contrario, forma el círculo apasionado dentro del cual el estado atrapa al sujeto" (Butler, Mecanismos 143). Si uno pierde una ilusión, es decir, la creencia en la posibilidad de algo, uno pierde la necesidad de probar que uno es inocente de ir en contra de ese algo que uno cree posible. Paradójicamente, el desencanto desestima la promesa de identidad pero se somete a la necesidad de probar inocencia. Esta forma de probar inocencia está regida por las coordenadas que el imaginario establece para la culpabilidad de la clase culta.

En la prensa, las acusaciones disponibles para la clase culta se fundamentaban más bien en la falta de creencia en la revolución como resultado de una racionalidad egoísta. Este tipo de recriminación abundaba en la prensa carrancista de 1915. Innumerables artículos en El demócrata, periódico fundado por Francisco Madero -pro-Carranza en 1915- se pronuncian contra los científicos y los revolucionarios egoístas. El 2 de

Revista Iberoamericana, Vol. LXXXI, Núm. 250, Enero-Marzo 2015, $125-139$ ISSN 0034-9631 (Impreso)

ISSN 2154-4794 (Electrónico) 
noviembre de 1915 en "Los científicos en pequeño" se definían las cualidades del científico como: "quien ruinmente lucra con la ignorancia, con la ambición, con la miseria, con la maldad y con la estupidez", "no querer o no saber trabajar honradamente, ser el eje de las arbitrariedades del comercio, con especialidad del mal comercio extranjero" [...] (Ramel3). El 23 de noviembre de 1915 en "Quienes son los verdaderos revolucionarios" se afirmaba que "muchos hay que se han creído revolucionarios y no lo son. Han ido a satisfacer apetitos", "Verdaderos revolucionarios son aquellos que han ido al campo de la lucha con sano corazón. Serenos y formidables a la vez, se han batido en la batalla sin temor" (n.p. 3). Solís posee el tipo adecuado de resolución interna, es decir la pasión por un ideal y un reposado desencanto, que es la forma de diferenciación de una ingenuidad brutal y de una conciencia deshonesta.

\section{ENTRE LA LEY Y EL CONTRATO}

El historiador Elías Palti comenta que en México a fines del siglo XIX existía una pugna entre una forma jurídica basada en la ley y otra basada en el contrato. La ley y el contrato presentan formas de regulación social opuestas: la ruptura de un pacto es un acto de disidencia (y por lo tanto no es punible), en cambio, la violación de una ley es un crimen (Legitimidad 348-49). Podemos ver que Cervantes y los de abajo se manejan bajo la lógica del contrato en la cual la disidencia y adherencia permite múltiples posiciones de la voluntad. Solís, en cambio, se mueve bajo la lógica de la ley. Bajo la lógica de la ley, la soberanía se asienta fuera de la voluntad ya que el Estado necesita bases más estables que las volubles voluntades. Butler se cuestiona por qué la formación del sujeto althusseriano parece solo tener lugar en una sumisión a la ley mediante la aceptación de sus exigencias de conformismo (Mecanismos 122); su teoría pregunta, "¿bajo qué circunstancias la llamada del nombre solicita esa media vuelta, ese movimiento de anticipación en dirección a la identidad?" (122). En el caso de Solís, la formación del sujeto se da por una sumisión a la ley sin -o por medio de la no aceptación de-las demandas de conformidad porque aceptar la demanda de conformidad implica someterse al viejo régimen basado en líderes carismáticos. Azuela compagina el desencanto de Solís basado en las condenas previamente asignadas a los científicos en el porfirismo y a los falsos revolucionarios en el carrancismo. ${ }^{5}$ Someterse a la ley implica afirmarse como sujeto; no aceptarla implica reafirmar el sentido del yo por medio de la negación de un apego pasional. El desencanto en Los de abajo enfatiza un desencanto individual frente a una creencia colectiva. Se puede rehusar la ley en

\footnotetext{
Un solo detalle permitiría atribuir a Cervantes la identidad de carrancista. Pancracio cuenta que: "a mi me tocó de centinela... oí el ruido entre las yerbas y grité: ¿Quién vive? ... "Carranzo" respondió este vale... "¿Carranzo"?... No conozco yo a este gallo... Y toma tu Carranzo... le metí un plomazo en una pata" (Folletín 3, ed. crítica 159).
}

Revista Iberoamericana, Vol. LXXXI, Núm. 250, Enero-Marzo 2015, $125-139$ ISSN 0034-9631 (Impreso) 
nombre de una vinculación apasionada pero en Los de abajo se rehúsa la ley en nombre de una vinculación constituida por una falta de una pasión porque esa falta de pasión se entiende por racionalidad.

\author{
-Se ha cansado de la revolución? \\ -¿Cansado?... Tengo veinticinco años y, usted lo ve me sobra salud...¿Desilusionado? \\ Puede ser. \\ -Debe tener sus razones... (61)
}

La forma en que el desencanto conforma una moral es a través de "una disposición a no ser -una desubjetivación crítica- con el fin de desenmascarar la ley y mostrar que es menos poderosa de lo que parece" (Butler, Mecanismos 144). ¿Es este modo distinto habilitado por la ley un giro que resiste su señuelo de identidad? ¿Se opone su potencia a sus condiciones de emergencia?

La desilusión demanda una fortaleza espiritual que la desesperación no requiere. Es por eso que Solís recalca su salud y energía a diferencia de la desesperación del Sr. Ríos en Las Moscas, cuyas incertidumbres se basan en la insatisfacción de un beneficio personal. El Sr. Ríos cae rendido de agotamiento luego de preguntar(se) “¿Por qué Dios poderoso; yo, Donaciano Ríos, honrado hasta en los forros de mi chaleco recibo como recompensa a mi fidelidad a la patria, al hogar y a la fe de mis mayores, estos crueles sufrimientos? ¡Mentira! -exclama en voz alta- ¡Mentira, la justicia no es verdad! Aterrorizado entonces, como el creyente que acaba de blasfemar, tiembla de los pies a la cabeza pero eso mismo lo acaba de agotar y lo hace caer rendido en sueño dulce y profundo hasta el amanecer" (Azuela, Obras completas 881-82). Solís actúa como el reverso del super-hombre nietzscheano, no manifiesta su voluntad de poder sino que posee la fuerza para desautorizar la voluntad de poder ajena. Las emociones que pone en escena Solís son las emociones apropiadas a un estatus. Estas reglas de emoción toleran la espontaneidad acrítica de ciertos personajes pero condenan el idealismo retórico. Esperan transmitir una idea de sinceridad que se amolda a las reglas de sentimiento de una comunidad en particular y al mismo tiempo deploran ciertas "performance" de sentimientos dentro de su misma comunidad, por tratarse de una incongruencia con una cierta forma de racionalidad. Esto resulta así porque una vez perdida cierta ilusión, la "performance" de la creencia en la misma denota deshonestidad. Solís señala esta incongruencia al encontrarse con Cervantes: "No comprendo como el corresponsal de $E l$ Pais [refiriéndose a Cervantes] en tiempo de Madero, el que escribía furibundos artículos en El Regional, el que usaba con tanta prodigalidad del epíteto de bandidos para nosotros, milite en nuestras propias filas ahora" (60-61). Asimismo, la pérdida de ilusiones implica una forma de superioridad. El abogado Bocanegra de Las moscas lo explica: "Con todo algo hemos ganado, ¿No ha pensado el Sr. Ríos en sus horas amargas de desesperanza que nuestro estoicismo nos ha hecho crecer? ¿Que algo superior a nosotros mismos se

Revista Iberoamericana, Vol. LXXXI, Núm. 250, Enero-Marzo 2015, $125-139$ ISSN 0034-9631 (Impreso)

ISSN 2154-4794 (Electrónico) 
nos ha revelado en nuestra serena actitud?"; el narrador concluye: "El Sr. Ríos confiesa ingenuamente su impotencia para encontrar tal superioridad" (880). El desencanto se confunde con una serenidad heroica y al mismo tiempo impide la reducción del acto de subjetivación (el darse vuelta de la interpelación) a la necesidad de reconocimiento (el acercamiento hacia “esa voz"). Es decir, el desencanto en Solís busca quedar absuelto de toda identificación con las convicciones revolucionarias de última hora.

El desencanto en Los de abajo es una forma de relación con la ley que se somete a una necesidad de probar inocencia propia de la clase culta. El llamado de la ley, la forma en que esta interpela al sujeto, no es igual para todos. Rodríguez en Los Caciques dirá: "mientras los proletarios derraman su sangre a torrentes para dejar de ser siervos, los intelectuales empapan la prensa con su baba asquerosa de rufianes" (844). Hay un lenguaje que establece las coordenadas del deseo de reconocimiento e inocencia. El desencanto no es solamente una pérdida de ilusiones ni es universalmente una frustración sino que manifiesta una preocupación por imbuir una sensibilidad crítica.

Schiller, intentando imbuir de sensibilidad las mentes de las clases privilegiadas al término de la Revolución Francesa hace explícita una selectiva sensibilidad cuando diferencia entre el 'salvajismo' de las clases más bajas y la apatía de las clases cultas. Los individuos pertenecientes a las primeras se hallan gobernados por una sensibilidad ciega mientras que los de las clases cultas "se escudan complacientemente en el uso hipertrofiado de una razón que no es capaz de ir más allá de la producción mecánica de conceptos y leyes" (Schiller 25-29). De manera similar, el espacio en el que el sujeto literario latinoamericano emerge a principios de siglo xx: "encontrará su voz por el reverso -y como crítica- de la racionalización; su voz cargada de valor "espiritual" precisamente en un mundo desencantado y mercantilizado" (Ramos 81). Es así que de acuerdo a Julio Ramos, la literatura latinoamericana se legitima a principios de siglo como lugar de lo otro de la racionalización. (158) El valor semántico de la palabra "científico" a principios del siglo xx en México era entre los liberales que se oponían al régimen de Porfirio Díaz marcadamente peyorativo. En parte como consecuencia del apodo dado a un grupo de empresarios dispuestos a monopolizar y modernizar el negocio agrario llamados "los científicos" (Rutheford 20). En 1925, prevalecía la enjundia, el día 4 de febrero en el diario Excelsior, el doctor Quevedo de Zubieta proponía un médico como víctima social para la tumba del mártir desconocido y afirmaba: "Ante él se deben traer a los que en el globo tachan a la medicina de profesión mercantil” (Quevedo Zubieta 1). La valoración de la sensibilidad de la cual hace eco Azuela se dirige a un lector moderno postulándose como el reverso de la racionalización. En "Cien años de novela mexicana" Azuela le critica a Luís Inclán que los rancheros de su novela Astucia "carecen de ideas generales, ningún conflicto espiritual los inquieta” (Azuela, Cien 594). Sobre Baile y cochino de José Tomás Cuéllar (seudónimo Facundo) afirma, "La emoción estética que el lector moderno exige de la novela no la supo dar Facundo, así como tampoco sus predecesores" (Azuela, Cien 611). Como especificamos en la lectura nietzscheana del

Revista Iberoamericana, Vol. LXXXI, Núm. 250, Enero-Marzo 2015, 125-139 
desencanto, este sentimiento se halla íntimamente ligado a la racionalidad. No es una negación de la racionalidad sino una mediación entre la modernidad y las áreas dejadas fuera que tanto Cervantes como Solís, y aun el mismo Mariano Azuela transitan. Solís es la sensibilidad a imbuir.

La idea de la ley crea en los sujetos unos estados afectivos que impulsan la conducta práctica en una dirección. El problema es que lo que se debatía en 1915 y años subsiguientes era precisamente cuál era la ley. Guisa Acevedo en La revolución y su Luis Cabrera atribuye el fracaso de la revolución de Obregón a "una aplicación estricta de la ley; que se ponía dentro de la ley y excomulgaba a Carranza por sus atentados contra el derecho" (34). El periódico Excelsior en un editorial anónimo publicado el 6 de febrero de 1925 con motivo del aniversario de la Constitución de febrero de 1913 clarifica aún mejor lo dicho por Guisa Acevedo:

\begin{abstract}
Ya el maderismo traía gérmenes de verdadera revolución social que se desplegaron prodigiosamente en el seno del "constitucionalismo", imprimiendo a este orientaciones oficialistas radicales; y por eso cuando triunfó el movimiento armado y abandonó el país el general Huerta, los moldes de [la Constitución de 18] 57 parecieron a los revolucionarios victoriosos, inadecuados para dar cabida a sus nuevas tendencias, y así la constitución que pretendían reestablecer, era ya documento inservible.
\end{abstract}

Los lenguajes políticos se habían posicionado de tal manera que emular el espíritu de progreso que tuvo en su tiempo la constitución de 1857 resultaba reaccionario, aún cuando estas medidas tendieran a abolir el sistema de caudillaje favorecido por Porfirio Díaz. La vinculación desapasionada manifiesta entonces no una auto-objetivación psicológica de Azuela en el personaje de Solís sino la ubicación de Solís como un tipo ideal en una objetivación de una época, "como reflejo de un estado social" (Azuela, Epistolario 275). La posibilidad de una visión crítica de la ley queda delimita por lo que podría ser entendido como un deseo previo de la ley, una complicidad pasional sin la cual ningún sujeto puede existir (Butler, Mecanismos 121). La crítica desapasionada de Solís implica una pasión que niegue la pasión para hacer que el sujeto alcance la madurez política -no bajo una creencia en la ley sino bajo una complicidad con la ley. El sujeto político en este caso no puede existir sin una complicidad desapasionada con la ley. La complicidad con la ley se hace necesaria ya que si se critica la ley hasta destruirla, la ley no puede constituir al sujeto. El desencanto es el resultado de un acto de concientización de tensiones existentes.

Laura García Moreno en "Melancolía y desencanto en Pedro Páramo" relaciona el sentimiento de desencanto con una marca de la entrada de México en la modernidad: "la aceptación de la desilusión asociada con la ruina con la que culmina la novela y el reconocimiento del vacío y la violencia que subyacen a la fundación de la nación moderna funcionan como motor del pensamiento histórico y de la mirada melancólica

Revista Iberoamericana, Vol. LXXXI, Núm. 250, Enero-Marzo 2015, $125-139$ ISSN 0034-9631 (Impreso)

ISSN 2154-4794 (Electrónico) 
auto-analítica" (513). Los de abajo se anticipa a este pensamiento moderno. El desencanto puede leerse como una expresión de perspicacia en cuanto a la paradoja ética que significa participar en la política de la revolución. "La devoción al carisma del profeta, líder guerrillero, demagogo en la asamblea o en el parlamento, significa que se reconoce personalmente al líder como conductor de hombres por un 'llamado interior'. Los hombres no le obedecen en virtud de la tradición o de lo estatuido, sino porque creen en él" (Weber, El político 60). El desencanto surge al comprender que "el medio decisivo de la política es la violencia" (116) y que "no es cierto que el bien sólo puede resultar del bien y el mal del mal, sino que con frecuencia ocurre lo contrario" (118). Este desencanto implica que para que el "yo" emita su crítica, debe primero entender que el "yo" mismo depende de un deseo cómplice de la ley que asegura su propia existencia (Butler, Mecanismos 121). Al pactar con medios violentos con fines políticos el "líder no es enteramente dueño de los resultados de su actividad, pues debe plegarse a las exigencias de sus partidarios, exigencias que consideradas éticamente pueden resultar bajas" (Weber, El político 121). Solís cree sin sacrificar el intelecto, es decir desapasionadamente. Las emociones que pone en escena Solís son las emociones apropiadas a una necesidad moderna. Su posición crítica sólo puede existir una vez que dirige su mirada hacia la ley ante la cual somete su necesidad de probar inocencia.

\section{CONCLUSIÓN}

La vinculación desapasionada por la ley forma parte de una emoción que señala un tipo especial de relación con la ley. La honestidad, legitimidad y valentía no pertenecen a un grupo específico -villistas, carrancistas, porfiristas, zapatistas- más bien es una "performance", "una conducta dos veces actuada" que marca la pertenencia de sus actores a un grupo legítimo en relación con la ley. El día de la última entrega de Los de abajo en El Paso del Norte -21 de noviembre de 1915- el poema "León Guzmán" publicado por el sobrino de Porfirio Díaz da cuenta de este desencanto, y esta necesidad de reconocimiento en su relación con la ley y con el pueblo:

\footnotetext{
Alto, severo, pálido, arrogante

iluminado por la luz fébea

marcha el Bayardo de la nueva idea, de Libertad el caballero andante.

Un entusiasmo loco y delirante

y fe viva en sus ojos centellea

por la Constitución -su Dulcinea-

que él redactó con pluma de diamante.

Los Derechos del hombre en el sublime

Código están, y a México redime:

¡el hombre libre, se levanta erguido!
}

Revista Iberoamericana, Vol. LXXXI, Núm. 250, Enero-Marzo 2015, 125-139 


\begin{abstract}
Después de tanto esfuerzo sobrehumano.
¿qué premio tiene el grande ciudadano?

¡la ingratitud del pueblo y el olvido!

(Martínez Dolz)
\end{abstract}

Se puede percibir un desencanto ligado a una vinculación desapasionada por la ley. La vinculación apasionada en el acto interpelativo en "La conciencia nos hace a todos sujetos" predispone una subjetivación del individuo, pero al mismo tiempo constituye el núcleo de la subjetividad, es decir la posibilidad de resistencia. En la vinculación desapasionada por la ley que he señalado en este ensayo, el núcleo que predispone la vinculación con la ley y al mismo tiempo constituye el núcleo de la subjetividad es el desencanto.

Butler establece la vinculación apasionada como forma de no reducir el acto de subjetivación a un solo cuerpo (el del amo). Hasta cierto punto desde el siglo XIX, diversas formas de regulación social en México se debatían precisamente eso: en torno a qué cuerpo reducir el acto de subjetivación de la soberanía. En 1848, en un artículo en El Universal el intelectual mexicano Lucas Alamán aseveraba la irracionalidad del principio de soberanía popular argumentando que no se podía ser amo de la ley y esclavo de ella al mismo tiempo. Lucas Alamán juzgaba asimismo un sinsentido la restitución de tierras ya que obligaba a una compensación ad infinitum y se prestaba a confusión quienes eran los adecuados destinatarios de la misma (Palti, Legitimidad 143). Este planteo en torno a la restitución de tierras aparece en "El rebelde" (1929) de Azuela. Palti encuentra la paradoja señalada por Alamán en la idea medieval del soberano bajo la cual uno es subjectum (sólo así puede hacer la ley) y subjectus (sólo así puede ser soberano) (La nación 142-43). Si en el siglo xIX las discordias en torno al termino "nación" eran alimentada a partir del concepto "pueblo", a comienzos del siglo xx el término "revolución" encontraba su fuente de discordias en el concepto de "ley". Solís expresa la futilidad de la voluntad de poder con respecto al problema de la soberanía popular y da cuenta de una relación conflictiva entre la Revolución Mexicana y la ley.

El desencanto de principios de siglo en torno a la Revolución Mexicana tiene una muy clara figura de culpabilidad y una promesa de identidad o reconocimiento a partir de la cual probar inocencia. El desencanto no se "produce" simplemente, sino que obedece a una necesidad cuyas coordenadas están regidas por un lenguaje. Ese lenguaje determina "esa" necesidad de probar inocencia para constituirse en ese hipotético sujeto butleriano que, habilitado por la ley, se hace de espaldas a ella oponiéndose a su señuelo de identidad y a las condiciones de su emergencia (Mecanismos 144). En la creencia apasionada por la ley del acto de subjetivación, el desencanto constituye un exceso. Este exceso que se incorpora en el reconocimiento afirma un hábito de obediencia que rebasa la razón y la creencia mientras que devalúa lo violento y lo iluso como aquello que obstaculiza el establecimiento de un sistema jurídico. Es posible percibir que

Revista Iberoamericana, Vol. LXXXI, Núm. 250, Enero-Marzo 2015, $125-139$ ISSN 0034-9631 (Impreso)

ISSN 2154-4794 (Electrónico) 
Azuela retoma el problema de la incomprensión del sentido del término "nación" pero lo reescribe dentro del término "revolución". Al retomar el tema de la irracionalidad y la soberanía popular incorpora a algunos individuos "cultos" introduciendo así el factor del desencanto. Solís lleva la marca del desencanto señalando un límite simbólico en su identidad ideológica. Esta identidad ideológica expresa una forma de percibir un problema. El desencanto de Solís mantiene un núcleo de incertidumbre ante las pasiones deshonestas o ingenuas de las otras subjetividades.

\section{OBRAS CITADAS}

“Actos de los zapatistas al retirarse de la capital". La Prensa (México, 8 febrero 1915): 1. Austin, J. L. How to Do Things with Words. Cambridge: Harvard UP, 1962.

Azuela, Mariano. Cien años de novela mexicana. México: Fondo de Cultura Económica, 1958.

Mariano Azuela: Epistolario y archivo. Recopilación, notas y apéndices de B. Berler. Beatrice Berler, ed. México: Univ. Nacional Autónoma de México, Centro de Estudios Literarios, 1969.

Los de abajo: Edición crítica. Jorge Ruffinelli, coordinador. 2ª ed. Madrid: Colección Archivos, 1996.

Obras Completas. México: Fondo de Cultura Económica, 1958.

Brioso y Candiani. "Las causas de nuestra Revolución”. El Demócrata (México, 26 noviembre 1915): 3.

Butler, Judith. Bodies That Matter: On the Discursive Limits of "Sex." New York: Routledge, 1993.

“Conscience Doth Make Subjects of Us All." Yale French Studies 88 (1995): 6. Cuerpos que importan. Sobre los límites materiales y discursivos del "sexo".

Buenos Aires, Paidós, 2002.

Mecanismos psíquicos del poder: teorías sobre la sujeción. Madrid: Ediciones Cátedra, 2001.

Casey, Edward, y Melvin Woody. "Hegel and Lacan." Hegel's Dialectic of Desire and Recognition: Texts and Commentary. John O'Neill, ed. Albany: State U of New York P, 1996. 223-232.

De la Torre, A. Rivera. “La neutralidad incivil”. La Prensa (México, 14 febrero 1915): 3. “El Sr. Carranza ante la Convención”. El Pueblo (México, 5 octubre 1914): 3.

Felluga, Dino. "Modules on Lacan: On Desire." Introductory Guide to Critical Theory. 31 de enero, 2011. Purdue U. Web. 22 de enero, 2012.

Fornet, Jorge. "La Narrativa cubana entre la utopía y el desencanto". Hispamérica 32/95 (2003): 3-20.

García, Mario T. Luis Leal: An Auto/biography. Austin: U of Texas P, 2000.

Revista Iberoamericana, Vol. LXXXI, Núm. 250, Enero-Marzo 2015, $125-139$ ISSN 0034-9631 (Impreso) 
García-Moreno, Laura. "Melancolía y desencanto en Pedro Páramo". Revista canadiense de estudios hispánicos 30/3 (2006): 497.

Guisa, y A. Jesús. La revolución y su Luis Cabrera. México: Editorial Polis, 1975.

“La afectación”. El Pueblo (México, 6 octubre 1914): 5.

Martínez Dolz, Félix. “León Guzmán”. El Demócrata (México, 21 noviembre 1915): 5.

Nietzsche, Friedrich. Sobre la utilidad y el perjuicio de la historia para la vida: II intempestiva. Biblioteca nietzscheana, 2. Madrid: Biblioteca Nueva, 1999.

Palti, Elías J. La invención de una legitimidad: razón y retórica en el pensamiento mexicano del siglo XIX: (un estudio sobre las formas del discurso político). México, D.F.: Fondo de Cultura Económica, 2005.

La nación como problema: los historiadores y la “cuestión nacional”. Buenos Aires: Fondo de Cultura Económica, 2003.

"Para ser amada. Renuncias provechosas". El Pueblo (México, 6 octubre 1914): 5.

Phelan, Peggy. Unmarked: The Politics of Performance. London: Routledge, 1993.

Quevedo Zubieta "El martirio médico desconocido". Excelsior (4 febrero 1925).

"Quienes son los verdaderos revolucionarios". El Demócrata (México, 23 noviembre 1915): 1.

Ramos, Julio. Desencuentros de la modernidad en América Latina: literatura y política en el siglo XIX. México: Fondo de Cultura Económica, 1989.

Ramel. “Los científicos en pequeño". El Demócrata (México, 2 noviembre 1915): 3.

Robe, Stanley. Los de abajo. Jorge Ruffinelli, ed. Buenos Aires: Fondo de Cultura Económica, 1992.

Ruffinelli, Jorge. Literatura e ideología: el primer Mariano Azuela, 1896-1918. México, D.F: Premia Editora, 1982.

Rutherford, John. Mexican Society During the Revolution: A Literary Approach. Oxford: Clarendon P, 1971.

Schiller, Friedrich. On the Aesthetic Education of Man: In a Series of Letters. Elizabeth M. Wilkinson, and L A. Willoughby, trads. Oxford: Clarendon P, 1968.

Taylor, Diana. "Hacia una definición de performance" ponencias. <http:// performancelogia.blogspot.com/2007/08/hacia-una-definicin-de-performance. html $>12 / 02 / 14$.

Thiebaut, Carlos en El desencanto como promesa: fundamentación, alcance y límites de la razón práctica. 17-39. Rocío Orsi, ed. Madrid: Biblioteca Nueva, 2006. 51-79.

Weber, Max. From Max Weber: Essays in Sociology. Hans H. Gerth, and C W. Mills, eds. New York: Oxford UP, 1946.

El político y el científico. Buenos Aires: Editorial Altamira, 2007.

Revista Iberoamericana, Vol. LXXXI, Núm. 250, Enero-Marzo 2015, 125-139 
